\title{
Effect of Class wide peer tutoring on learning Backstroke swimming skills and attitude to work in small groups
}

\author{
DR / Wagdy Mohammed Abdel Wahab \\ Faculty of physical education- Helwan University \\ Associate Professor at the physical education department, \\ Qassim University. Currently loaned.
}

\begin{abstract}
The study aimed to investigate the effect of Class-wide peer tutoring cooperative learning on backstroke learning swimming performance of novice pre-service students at department of physical education and kinesiology department at Qassim University. The study sample were 60 novice students at the first year and second semester (age= 18.4 SD=1.9) were randomly assigned in two groups (experimental and control) each group had 30 students. Experimental group exposed to Class wide peer tutoring cooperative learning and control group exposed to traditional teaching method. The intervention program lasted for 6 weeks. Students evaluated in 25-meter backstroke swimming performance with pull boy between their thighs. The results showed there is significant differences between the two groups in backstroke swimming performance. The results also indicated that the experimental group had more positive attitude to work together in small group and had positive interaction between. The study recommended to use Class wide peer tutoring cooperative learning to teach backstroke swimming performance to preservice novice students at the faculties and departments of physical education because the students at the peer tutoring group enjoyed the active learning engagement in swimming lectures than traditional methods, and had more positive attitude to work together.
\end{abstract}

\section{Introduction}

Cooperative is human nature means individuals work together to achieve their goals, which called cooperation. Cooperative defined to individuals work together to achieve a certain goal(Schunk, 2012). Cooperation have three important principles, work together, accountability, and positive interdependence(Johnson \& Johnson, 2016). (Felder \& Brent, 2007)indicated that the cooperative learning (CL) refers to students work together to achieve education goals, assignments, or any other aspects under certain conditions and clear criteria to judge their achievements. According to education literatures and philosophy cooperative learning can enhance students' outcomes and students' opportunities to overcome some learning and educational barriers(Schunk, 2012). Cooperative learning is the active engagement strategy used in classroom(Johnson \& Johnson, 2016). Peer tutoring have many attributes of cooperative learning, like students work together to achieve their tasks and goals, and free interactions(Dyson \& Casey, 2016). Physical education supports cooperative learning to achieve some goals especially performance aspects. Sports skills performance acquisitions is the most important issues in preservice Physical education (PE) teacher preparation competencies. Acquisitions these skills is the core of the PE teacher's competence, hence every physical education institutional responsible to realize these competencies, and give more attention to improve pre-service student's sports skill performance to prepare students to teach in the future.(Maheady, Harper, Mallette, \& Karnes, 2004) indicated the teacher pre-service preparation in last decades faced many critics from community to failure modify preparation program to suit practical reality. Teaching methods and strategies should be a part of the pre-service PE teacher preparation before going to practice these competencies in the future. 
Swimming is the complex skills demands efforts toward the tasks, team cooperation, good observation and coordination between all members' who are responsible in learning process.(Lepore, Columna, \& Lizner, 2018) peer tutoring one of the most effective strategies which organize and apply in PE. Peer tutoring Is the use of peers in organized activities to provide more opportunities for students to practice what they have learned in the content. The peer tutoring differs from cooperative learning in that required the instructor teach students how they can perform or act the required activities, and students behave as Student and teacher. (Barker, Wallhead, \& Quennerstedt, 2017).

Peer tutoring in our study mean to use peers in organized activities to provide learners more opportunities to practice what they have learned in the swimming classes as trainees and trainers. (Dong, Hwang, Shadiev, \& Chen, 2018) indicated that the activities group in peer tutoring intervention showed positive interactions and more supports to their classmates than traditional methods, like social supports and students willing to help each other to realize important knowledge required to achieve learning topics.(Dong et al., 2018; Mubark, Elrubiaan, \& Elhayek, 2009)

There were a large body of the Arabic and English literature demonstrates the effectiveness of peer tutoring in student's attitude and wide range of learning variables. The study of (Mubark et al., 2009) indicated that peer tutoring and multi levels intervention group had more positive effects in streamline position, freestyle kicking, and backstroke kicking skills than control group after 8 weeks swimming program. (Madou \& Iserbyt, 2018) examined effect of peer tutoring on freestyle swimming performance, task time achievement, and physical activity levels in four swimming learning classes, the results showed positive effects on swimming performance, time on task, and physical activity levels acquired in swimming classes. (Dong et al., 2018) suggested employing peer tutoring learning strategies especially when students learn difficult topics. examined the effect of class wide on support classroom active learning, The study confirmed that the class wide one of most important strategies used to facilitate learning before students engagement in learning processes and group interactions. (Mirzeoğlu, 2014) confirmed that the class wide is the key to success in achieving classroom goals. (Ayvazo \& Ward, 2009) showed the class wide peer tutoring had positive effect in volleyball learning performance. This finding consistent with the study of (Hawkins, Musti-Rao, Hughes, Berry, \& McGuire, 2009)that indicated that the active learning engagement in class wide can improve students' performance and academic achievement.

\section{Search problem}

Physical education field studies supported students active engagement in learning processes in all levels, but in pre-service physical education teacher had more doubtable and concerns. Teacher must examine Effective Teaching methods and learning strategies that help students to achieve their goals at the same time it suits the student's characteristics, Facilities, and stuff members who is responsible of the all education process. There is no strategy better than others, but there is strategy that achieves some learning aspects more than others, and teacher should take all these aspects into the consideration when selecting appropriate strategy(Eldessouki, 2016)

Scientific research in the field of the teaching and learning swimming support active engagement in learning processes, especially with older learners like college students. The peer tutoring in 
swimming needs students to have previous experiences about learning topics, because swimming is sport that need high skills and safety procedures. Peer tutor can provide good and rich experience and motivation for pre-service teacher, therefore PE pre-service teacher preparation programs should include effective strategies to prepare teachers to teach in challenging ways that include innovative teaching, practice, and strategies methods or experiment new instructional strategies. Strengthen swimming learning becomes important for the pre-service teacher, to that learners get more motivation and having fun in swimming lecture. Peer tutoring consists of three stages: theoretical and cognitive explanation, then exercise and repetition to master the skill(Lee, Morrone, \& Siering, 2018). These stages mean that students need suitable peer tutoring, and duration of practice. In swimming, there little studies using active engagement learning strategies especially peer tutoring strategy with children and exceptional population and there were lack of studies examined class wide peer tutoring with under graduate students in swimming classes especially in backstroke swimming. The study aimed to identify the effects of Class-wide peer tutoring in learning backstroke swimming, and identify student attitudes towards working in small groups. The researcher hypotheses the class wide peer tutoring would facilitate the learning backstroke swimming and will enhance students' attitude to work together in small groups as responses to class wide peer tutoring learning strategy.

\section{Aims of the study: -}

The study aimed to identify the Effect of class-wide peer tutoring learning teaching methods on pre-service physical education teacher achievement of backstroke swimming learning skills, and student attitudes to work together in peer tutoring groups.

\section{Hypothesis:-}

1. There are significant differences in learning backstroke swimming skills between students who exposed to peer tutoring learning and those who are exposed to traditional methods to peer tutoring groups.

2. There are significant differences in attitude to work between students who exposed to peer tutoring learning and those who are exposed to traditional methods to peer tutoring groups.

\section{Methods: -}

The study subjects were 60 students from physical education and kinesiology department at Qassim University, aged 18-20, $\mathrm{M}=18.4( \pm .89)$, randomly divided in two groups, intervention group (peer tutoring group, $\mathrm{N}=30$ ) and control group (traditional method group, $\mathrm{N}=30$ ).

\section{Measures:-}

\section{The Backstroke swimming learning skills: -}

The Backstroke swimming learning skills measured two times at the beginning of the intervention (pretest) and the end of the intervention (post-test) to identify the effect of peer tutoring intervention. All the subjects swim $25 \mathrm{~m}$ backstroke from inside of the pool. All participants videotaped with Cannon Digital Camera Canon model EOS Rebel T7 DSLR from the side of the pool with 45 degree above the subject, and three meter away from. The subject's performance 
evaluated by two professional swimming instructors with 15 years' experience of the field of learning swimming. The observers checked 5 Backstroke variables techniques, these variables were head position, head stability, body rotation, hand exit of the water by thumb, hand enter the water by little finger, recovery with extended hand. Five trails for each subject had recorded, the trail score were one if the students realized performance criteria and were Zero if he did not achieve the performance criteria. The total scores of these 5 trails added together to calculate a total trials score.

\begin{tabular}{|c|l|l|}
\hline Table.1 Evaluation of backstroke swimming skills checklist & & \\
\hline 1. head position & & \\
\hline 2. $\quad$ body rotation, & & \\
\hline 3. hand exit of the water by thumb, & & \\
\hline 4. hand enter the water by little finger, & & \\
\hline 5. recovery with extended hand, & & \\
\hline
\end{tabular}

Validity and Readability: -

Reliability of instructors' observation checked at the start of the intervention. The researcher taught two observers how to observe and record performance variables. The observers checked the samples at random matter, each subject coded by number with hidden names and groups. The observer watched the videotaped and evaluated backstroke performance on standardized techniques criteria which researcher had made previous of the study. In the pilot study, the observer trained to evaluate 16 pre-service students backstroke performance through the checklist criteria. Intra reliability observation calculated through person correlation coefficient, intra agreement between two observers were .82 of the total checklist evaluation, and this score were acceptable to observers to evaluate the performance.

\section{Working in small groups questionnaire}

Before and the end of the study, the subjects completed attitude to work in small groups questionnaire of 15 questions, the questionnaire designed to identify the students' attitude to work in small groups. The questionnaire evaluated 5 different elements measured successful group interaction, these dimensions are individual responsibilities, positive interdependence, group communication, facilitate peer, group efforts, and group functioning to achieve the task. The students' responded were 5 points Likert' scale from 1 (not happen at all) to 5 (always happen). Face and construct validity were checked, and questionnaire dimensions internal consistency were checked, Cronbach Alpha were 0.79.

\section{Data analysis: -}

- SPSS version 20 package used to analyze quantitative data. 
- Means and standard division calculated for both groups based on the responses of the questionnaire and backstroke swimming performance checklist results analyzed.

- Normal distribution and analysis of variance checked by Kolmogorov-Smirnov test.

- Homogeneity of variance checked by Bartlett test.

- Multivariate normality of variance showed no significant difference $(\mathrm{p}<.05)$ which indicate the normality of data variables, then the researched used parametric statistics.

- Independent sample T-test used to compare the effects of independence variable between two groups in backstroke learning swimming performance.

- Student's responses to questionnaire analyzed by MANOVA to identify the information of student's attitudes to work in small groups.

- The researcher determined significant level at .05 .

\section{Procedure: -}

- Thermometer were evaluated swimming pool water temperature.

- The duration of intervention were lasted to 6 weeks, two sessions peer week.

- The duration of each session were 60 minutes.

- All teaching sessions held in the Qassim University swimming pool.

- The learning program were identical for both groups.

- Leaning program consisted of backstroke swimming drills aimed to execute backstrokeswimming performance.

- The study were quasi-experiment of two groups (experimental and control).

- Upon completion the study, the researcher evaluated the results between pre and posttest for all groups, and compare between the two groups in the research variables.

Table. 2 means and standard deviation of pretest pre-service students' performance in backstroke swimming

\begin{tabular}{c|c|c|c|c|}
\hline Experimental group & Control group & T value \\
\hline Mean & SD value & Sean & SD \\
\hline
\end{tabular}


Table. 2 means and standard deviation of pretest pre-service students' performance in backstroke swimming

\begin{tabular}{l|l|l|l|l|l|l|}
\hline $\begin{array}{l}\text { Backstroke } \\
\text { swimming } \\
\text { performance }\end{array}$ & 12.91 & 2.17 & 13.21 & 2.91 & 0.408 & 0.678 \\
\hline
\end{tabular}

Independent samples $\mathrm{T}$ test conducted to identify the differences between the groups in pretest backstroke swimming performance. The results illustrated in table. 2 shows no significant difference between the two groups (Intervention\& control) in pretest backstroke swimming performance evaluation.

Table. 3 means and standard deviation of pre-service students in attitude to work in small groups performance

\begin{tabular}{|c|c|c|c|c|c|}
\hline \multirow{2}{*}{ Dimensions } & \multicolumn{2}{|c|}{ Experimental group } & \multicolumn{2}{|c|}{ Control group } & \multirow{2}{*}{$\mathrm{T}$ value } \\
\hline & Mean & SD & Mean & SD & \\
\hline $\begin{array}{l}\text { individual re- } \\
\text { sponsibilities }\end{array}$ & 3.06 & 0.94 & 3.12 & 0.91 & 1.22 \\
\hline $\begin{array}{l}\text { positive interde- } \\
\text { pendence }\end{array}$ & 2.91 & 0.78 & 3.01 & 0.85 & 1.18 \\
\hline $\begin{array}{l}\text { group communi- } \\
\text { cation }\end{array}$ & 3.24 & 0.69 & 3.17 & 0.77 & 0.91 \\
\hline facilitate peer & 2.98 & 0.56 & 3.10 & 0.64 & 0.34 \\
\hline $\begin{array}{l}\text { Peer functioning } \\
\text { to achieve the } \\
\text { task }\end{array}$ & 3.72 & 0.71 & 3.81 & 0.59 & 0.90 \\
\hline Total & 15.91 & 2.17 & 16.21 & 2.69 & 0.82 \\
\hline \multicolumn{6}{|l|}{$\begin{array}{l}\mathrm{T}^{*}<.05 \\
\mathrm{P}^{* *<.01}\end{array}$} \\
\hline \multicolumn{6}{|c|}{$\begin{array}{l}\text { Pre-test a MANOVA analyses conducted to identify the differences between the two groups (in- } \\
\text { tervention and control) in } 5 \text { dimensions and total score of questionnaire. Results showed no sig- } \\
\text { nificant difference between the two groups in pretest score of attitude to work in small group's } \\
\text { questionnaire in all variables. }\end{array}$} \\
\hline
\end{tabular}

Results: -

Table. 4 means and standard deviation of posttest pre-service students' performance in backstroke swimming

group $\quad$ Pretest $\quad$ Posttest




\begin{tabular}{c|c|c|c|c|c|c|c}
7 & $\mathrm{~N}$ & Mean & $\mathrm{SD}$ & Mean & $\mathrm{SD}$ & $\mathrm{T}$ & P value \\
\hline $\begin{array}{c}\text { Experiment } \\
\text { al group }\end{array}$ & 30 & 12.91 & 2.17 & 22.84 & 3.09 & & \\
\hline $\begin{array}{c}\text { Control } \\
\text { group }\end{array}$ & 30 & 13.21 & 2.91 & 19.54 & 2.84 & 18.34 & 0.000 \\
\hline Total & 60 & 26.12 & 3.10 & 41.81 & 4.02 & & \\
\hline
\end{tabular}

Results in table.4 shows Independent sample T.test conducted to identify the difference between the two groups in post-test backstroke swimming performance. The results illustrated in table 5 shows $(\mathrm{t}=14.65, \mathrm{P}<.000)$ which indicated the significant difference between intervention and control group to intervention group. All results revealed that all participants in both groups had a positive effect on backstroke swimming performance

Table.5 means and standard deviation of pre-service students in attitude to work in small groups performance

\begin{tabular}{|c|c|c|c|c|c|c|c|}
\hline & \multicolumn{3}{|c|}{ Pretest } & \multicolumn{2}{|c|}{ Posttest } & \multirow{2}{*}{$\mathrm{T}$ value } & \multirow{2}{*}{$\mathrm{P}$} \\
\hline & $\mathrm{N}$ & Mean & SD & Mean & SD & & \\
\hline $\begin{array}{l}\text { Experiment } \\
\text { al group }\end{array}$ & 30 & 12.91 & 2.17 & 22.84 & 3.09 & 29.08 & 0.000 \\
\hline $\begin{array}{l}\text { Control } \\
\text { group }\end{array}$ & 30 & 13.21 & 2.91 & 19.54 & 2.84 & 25.19 & 0.000 \\
\hline
\end{tabular}

Paired sample T-test conducted to identify the differences between pre and posttest for both groups. The results in table. 5 shows a significant improvement for Experimental group between scores of pre $(\mathrm{M}=12.91, \mathrm{SD}=2.17)$ and posttest $(\mathrm{M}=22.84, \mathrm{SD}=3.09),(\mathrm{t}=29.08, \mathrm{P}<.000)$ and this improvement were significant difference to posttest score. The results in table.5 shows a significant improvement for control group between scores of pretest $(M=13.21, S D=2.91)$ and posttest $(\mathrm{M}=19.54, \mathrm{SD}=2.84),(\mathrm{t}=25.19, \mathrm{P}<.000)$ and this improvement were significant difference to post test score.

\section{Attitude to work in small groups: -}

Table.7 means and standard deviation of pre-service students in attitude to work in small groups performance

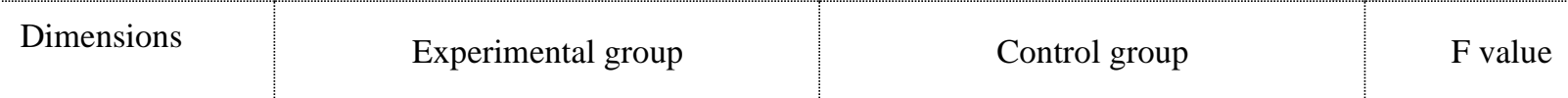




\begin{tabular}{|c|c|c|c|c|c|}
\hline & Mean & $\mathrm{SD}$ & Mean & SD & \\
\hline $\begin{array}{l}\text { individual } \\
\text { responsibilities }\end{array}$ & 4.21 & 0.85 & 4.12 & 1.12 & 1.24 \\
\hline $\begin{array}{l}\text { positive } \\
\text { interdependence }\end{array}$ & 4.57 & 0.69 & 3.97 & 0.93 & $4.91 *$ \\
\hline $\begin{array}{l}\text { group } \\
\text { communication }\end{array}$ & 3.85 & 0.81 & 3.76 & 3.73 & 0.74 \\
\hline facilitate peer & 4.3 & 0.81 & 3.67 & 0.43 & $6.91 * *$ \\
\hline $\begin{array}{l}\text { Peer functioning } \\
\text { to achieve the } \\
\text { task }\end{array}$ & 4.45 & 0.92 & 3.93 & 1.02 & $14.52 * *$ \\
\hline Total & 20.38 & 2.87 & 18.91 & 3.03 & $9.14 * *$ \\
\hline
\end{tabular}

A MANOVA analysis for repeated measures conducted to identify the pre-service student's attitude to work in small groups, and the differences between intervention and control group. The results in table.7 indicated there were significant differences between intervention and control group in three elements of questionnaire, positive interdependence, facilitate peer, and peer functioning to achieve the task, and there were no significant differences between two groups in individual responsibilities, and group communication. The total score indicated to significant difference between two groups in total attitude to work in small group questionnaire to experimental group.

\section{Discussion}

The study examined the class wide peer tutoring effects on novice pre-service students' learning backstroke swimming and student's attitudes to work in small groups. The results of the study indicated a significant positive effect of both interventions (peer tutoring and traditional teaching method) in backstroke swimming performance after 6 weeks of swimming lectures in Qassim university swimming pool. Results illustrated in table.5 compared between experimental and control group in posttest backstroke swimming learning performance, the result indicated a significant difference between two groups (intervention and control) in learning backstroke swimming performance to Experimental program. This result support use class wide peer tutoring intervention to teach backstroke swimming to novice pre-service physical education teacher. This improvement in intervention program could happened because class wide peer tutoring intervention increased active engagement between peers in swimming classes, and give pre-service students more times and opportunities to practice and learning backstroke swimming skills, which reflected in swimming learning performance. The results of this study consistent with studies of (Baepler, Brooks, \& Walker, 2014; Huang et al., 2017; Van Horne, Murniati, Gaffney, \& Jesse, 2012) which indicate the learning outcomes would improve with students active engagement and would produce a positive attitudes and motivation to learning subjects. Class wide peer tutoring in this study gave students many opportunities to express about themselves 
((Baepler et al., 2014)) and overcome of the large number of pre-service students in swimming classes. The results consistent with another explanation, the students in peer tutoring motivate their peers in swimming classes to achieve class tasks that raise physical activity levels in learning classes (Van Horne et al., 2012)

The study examined a pre-service student's attitude to work in small groups. The attitude questionnaire consisted 5 dimensions, individual responsibilities, positive interdependence, group communication, facilitate peers, and peer functioning to achieve a task. The results illustrated in table 9 showed a significant difference between intervention and control groups in dimensions of positive interdependence, facilitate peer, and peer functioning to achieve a task in addition the total score. The results of this study consistent with (Dong et al., 2018) indicated that the activities group in peer tutoring intervention showed positive interactions and more supports to their classmates. Results indicated there were no significant differences between two groups in individual responsibilities and group communication.

The study results confirmed that the class-wide peer tutoring is effective backstroke learning strategy for pre-service PE students, and enhancing students' attitude toward together in small groups. The results of study indicated peer tutoring intervention group have a higher level of the positive attitude to work in small groups in total score than control group, that can be explain through tutor interactions and class relationships, that the students choose the way that fit tutee in swimming classes and that require positive interdependence to achieve their common tasks. This findings consistent with the studies of (Eldessouki, 2016; Madou \& Iserbyt, 2018) which indicated that peer-wide tutoring interactions improved because tutors helping and motivate each other's to achieve their goals. This findings inconsistent with the study of (Rohrbeck, GinsburgBlock, Fantuzzo, \& Miller, 2003) which confirmed that peer tutoring is not effective strategy especially with younger students. Study results indicated there were no significant differences between the two groups (intervention-control) in individual responsibilities and group communication. This can explain through using traditional teaching methods could have influenced the individual responsibilities and group communication. this finding consistent with the(Dyson \& Casey, 2016) which indicated the traditional methods can improve student's characteristics

\section{Conclusion}

Class wide peer tutoring may provide the college instructor many opportunities to overcome large number of students and motivate students to active engagements in swimming classes. Future research should be investigate different educational and learning strategies and other peer's structure. Limitation of findings of this study must be consider because the small number of the study samples, therefore the study not represent the large number of undergraduate students population.

\section{References}

Baepler, P., Brooks, D. C., \& Walker, J. (2014). Active Learning Spaces: New Directions for Teaching and Learning, Number 137: John Wiley \& Sons.

Barker, D., Wallhead, T., \& Quennerstedt, M. (2017). Student learning through interaction in physical education. In: Sage Publications Sage UK: London, England. 
Dong, J.-J., Hwang, W.-Y., Shadiev, R., \& Chen, G.-Y. (2018). Implementing On-call-tutor system for facilitating peer-help activities. IEEE Transactions on Learning Technologies.

Dyson, B., \& Casey, A. (2016). Cooperative learning in physical education and physical activity: A practical introduction: Routledge.

Eldessouki, W. S. E. I. (2016). The Effect of Organized Peer Tutoring Strategy Based on Blended Learning in Developing Some Skills of Indesign Program and Problem-Solving Skills of Elearning Professional Diploma Students. arabic studies in education and psychology(78), 73-104.

Felder, R. M., \& Brent, R. (2007). Cooperative learning. Paper presented at the Active learning: Models from the analytical sciences, ACS Symposium Series.

Huang, M.-Y., Tu, H.-Y., Wang, W.-Y., Chen, J.-F., Yu, Y.-T., \& Chou, C.-C. (2017). Effects of cooperative learning and concept mapping intervention on critical thinking and basketball skills in elementary school. Thinking Skills and Creativity, 23, 207-216.

Johnson, D. W., \& Johnson, R. (2016). Cooperative learning and teaching citizenship in democracies. International journal of educational research, 76, 162-177.

Lee, D., Morrone, A. S., \& Siering, G. (2018). From swimming pool to collaborative learning studio: Pedagogy, space, and technology in a large active learning classroom. Educational Technology Research and Development, 66(1), 95-127.

Lepore, M., Columna, L., \& Lizner, L. F. (2018). Assessments and activities for teaching swimming: Human Kinetics.

Madou, T., \& Iserbyt, P. (2018). Effect of Pairing by Ability on Performance, Physical Activity, and Time-on-Task During Reciprocal Peer Teaching in Swimming. Physical Educator, 75(5), 756-773.

Maheady, L., Harper, G. F., Mallette, B., \& Karnes, M. (2004). Preparing preservice teachers to implement class wide peer tutoring. Teacher Education and special education, 27(4), 408418.

Mubark, A., Elrubiaan, A., \& Elhayek, S. (2009). The Effect of a Proposed Program for Learning Swimming based on Modern Styles of Teaching on Performance Skills and Swimming Anxiety among the Jordanian University students. Journal of Educational and Psychological studeies,JEPS, 3, 69-95.

Rohrbeck, C. A., Ginsburg-Block, M. D., Fantuzzo, J. W., \& Miller, T. R. (2003). Peer-assisted learning interventions with elementary school students: A meta-analytic review. Journal of Educational Psychology, 95(2), 240.

Schunk, D. H. (2012). Learning theories an educational perspective sixth edition: Pearson.

Van Horne, S., Murniati, C., Gaffney, J. D., \& Jesse, M. (2012). Promoting active learning in technology-infused TILE classrooms at the University of Iowa. Journal of Learning Spaces, $1(2), \mathrm{n} 2$. 